\title{
THE ROLE OF SOCIOCULTURAL COMMUNICATION IN THE HUMANITARIAN SCIENCES
}

\author{
Elyorbek Erkinjonovich Ablazov \\ Senior teacher of the chair of "The national idea, bases of morality and \\ Education of law" of Andizhan State University, Republic of Uzbekistan
}

Article DOI: https://doi.org/10.36713/epra2265

\begin{abstract}
In this article has been analyzed the role of socio cultural communication in the humanitarian sciences by the helping philosophical literatures and media materials as well.
\end{abstract}

KEY WORDS: communication, information era, virtual threats, worldview, youth, Internet, global community.

\section{INTRODUCTION}

In recent time's information era, the population of the world cannot live without information and communication networks. The Internet, which is becoming a daily demand of humanity, has been expanding day by day and increasing the number of its users. According to the International Observation Institute Daily Afisha, by the beginning of 2018 , for the first time in the history of the world, the number of Internet users has exceeded 4 billion. The number of Internet users increased by 250 million compared to 2017. The internet penetration rate is growing at least $20 \%$ every year, with Africa becoming the fastest growing region in the world.

The term "communication" is derived from two Latin words: sottshisapo, which means the transfer of information, messages, and sottsag, which can be translated as "connect, make common". Later, this word with minor transformations was borrowed by other languages. Already in the distant history, the understanding of communication as an infrastructure and as a social phenomenon, correlated with speech and other human activities, was shared. In the twentieth century, these trends persisted. They are reflected in modern reference books.

\section{METHODS}

In the modern world, the meaning of the word "communication" has acquired more strictly scientific outlines. So, in the Russian Sociological Encyclopedia edited by G.V. Osipova, this term is defined as "the transfer of information from one system to another through special material carriers, signals" [1].

In the Great Soviet Encyclopedia, the definition of communication can be found in several different articles. In the engineering context, this term refers to "communication lines, networks of the underground urban economy and transport". From a sociological point of view, communication is seen as "the transfer of information from person to person." Communication can be carried out as in the process of any activity, for example. production, and using a specialized form of speech activity or other activities using signs. Animals have simpler, not symbolic, but signaling methods of communication "[2, p.618].

A similar definition can be found both in the dictionaries of the modern Russian language, and in dictionaries and encyclopedic publications containing already outdated vocabulary. Communication in them is defined as a special form of communication, the way of communication, the exchange of information in society and (or) the animal world.

\section{RESULTS AND DISCUSSIONS}

It should be noted that, despite the differences in the interpretation of the term "communication" depending on the scope of its application, everywhere there is an indication of the process of exchanging information, transmitting messages. This can be considered the fundamental component of the concept under consideration. Any communicative activity is inextricably linked with the process of movement, 


\title{
EPRA International Journal of Research and Development (IJRD)
}

\author{
Volume: 5 | Issue: 2 | February 2020
}

\author{
- Peer Reviewed Journal
}

transmission, exchange of something [3].

The designated lexical meanings of the term correspond with the four areas of the possible manifestation of communicative activity. These areas include:

1. The transfer of information in human society, in the process of human social activity - social communication. This area is the area of understanding of the social sciences.

2. Biological interaction - biological communication. It is carried out in the living world with the help of various kinds of signals and other forms of information transfer. It is a field of study of biological sciences.

3. Ways of communication (air, water, land communication, networks underground utilities), form of communication (telephone, radio), other technical systems. In this case, we are talking about technical and technological issues of electronics, engineering, utilities economy, about such areas that are studied by the exact sciences [4, p.65].

Within the framework of communication theory, a definite system of categories has been formed. Depending on the considered level of theoretical generalization of communicative knowledge, this system includes a set of necessary scientific concepts and terms. The most generalized is the very concept of communication. So, in the 19th century, this term was used primarily in the framework of engineering and technical knowledge and was associated mainly with military engineering communications, involving a set of "ways, roads, means of communication places".

At the beginning of the last century, the word "communication" began to be widely used in various fields of social and humanitarian knowledge. This concept takes on a social meaning within the framework of a general scientific terminological system. In the literature, an explicit identification of the general concept of "communication" with the more particular one, "social communication," which is incorrect in terms of terminological rigor, is increasingly observed. Gradually, the biological and technical aspects of this term are leveled in the framework of the use of the word "communication" in the framework of social research.

One of the indicated ways of comparing these two terms is their almost complete identification within the framework of the socio-humanitarian context. Proponents of this approach are such famous Russian scientists as A.A. Leontiev, L.S. Vygotsky and V.N. Kurbatov. So, in a number of terminological dictionaries, the concept of communication is interpreted as "the way of communication, communication." According to researchers who adhere to this theory, semantically and etymologically, "communication" and "communication" are completely identical and can equally be used to describe the process of information exchange in human society.
The separation of the concepts of "communication" and "communication" formed the basis of the second approach. A similar opinion is shared, for example, by the famous Russian philosopher M.S. Kagan. In his writings, the researcher expresses the idea that at least two key factors can be distinguished based on which the separation of communication and communication will be natural. The first is the fact that communication is exclusively an information process - the transmission of certain data through communication channels. Communication is not limited to the fact of data exchange. This concept includes practical, material, spiritual and informational components. Secondly, they are different in the nature of the connection that appears between interacting systems [5].

\section{CONCLUSION}

It is worth noting that not all researchers agree with the hypothesis put forward about the relationship between communication and communication. Some, including A.V. Sokolov, in contrast, argues that communication is only one form of communication. At the same time, he proposes to base the classification of forms of communicative interaction on the goals of the participants in communication. Obviously, on the basis of this criterion, the following options for the relationship between individuals can be distinguished:

- the object-subject form of interaction is characteristic of imitation. In this type of communication, the recipient consciously chooses communicator as a role model. However, the object itself imitations at the same time may not even know about the fact of their participation in any or communication process;

- subject-subject relationship is expressed as a dialogue equal participants. It is this form of interaction between communication partners, according to Soloviev, is communication;

- the subject-object form of interaction is characteristic of management as one of the types of communication activities. As part of this type of relationship, the communicator perceives the recipient only as the object of informational impact, a means of achieving their goals. Also important concepts of communication theory are the concepts of "information", "communication space" and "communication time".

\section{REFERENCES}

1. Bolshaya Sovietskaya Encyclopedia / Ch. ed. A.M. Prokhorov, $3^{\text {rd }}$ ed. T. 12. - M : Publishing house "Soviet Encyclopedia", 1973. - 618 p.

2. Sokolov A.V. The general theory of social communication / A.V. Sokolov. - St. Petersburg: Mikhailov Publishing House, 2002.-P. 61.

1. 3.Bykov A.Yu. What is communication // Bulletin of the Ural State University. 2006. - No. 40 (19) .- P. 86-97.

3. Brodyansky D.L. Human. The culture. Society/D.L. 


\section{EPRA International Journal of Research and Development (IJRD)}

Volume: 5 | Issue: 2 | February 2020

Brodyansky. - Vladivostok: Publishing House of the Far Eastern University, 2010. - P. 90.

4. Morozov I. A. National-cultural specificity of communicative behavior / I.A. Morozov // IV International Student Electronic Scientific Conference "Student Scientific Forum". - M.: Russian Academy of Natural Sciences, 2012 